\title{
Upper limb muscle overgrowth with hypoplasia of the index finger: a new over-growth syndrome caused by the somatic PIK3CA mutation c.3140A $>\mathrm{G}$
}

\author{
Mohammad M. Al-Qattan ${ }^{1,2+}$, Ali Hadadi ${ }^{3 \dagger}$, Abdullah M. Al-Thunayan², Ahmed A. Eldali²
} and Mohammed A. AlBalwi $i^{3,4,5^{*}}$

\begin{abstract}
Background: Scientists have previously described an overgrowth syndrome in Saudi patients and named it 'Upper limb muscle overgrowth with hypoplasia of the index finger' syndrome.

Case presentation: We describe a new case and document that the syndrome is caused by the somatic PIK3CA mutation c.3140A>G, p.His1047Arg. We also recruited one of the previously reported cases and found the same somatic mutation in the affected muscles. A wider classification of 'PIK3CA-related pathology spectrum' is presented which includes cancer, benign skin lesions/tumors, Cowden syndrome, isolated vascular malformations and various overgrowth syndromes. The latter entity is sub-divided into 3 sub-groups: overgrowth with brain involvement, overgrowth with multiple lipomatosis, and overgrowth without brain involvement/multiple lipomatosis.

Conclusion: Our literature review indicated that "upper limb muscle overgrowth with hypoplasia of the index finger" is not as rare as previously thought to be. This overgrowth syndrome is unique and is caused by the somatic PIK3CA mutation c.3140A>G.
\end{abstract}

Keywords: Muscle, Overgrowth, PIK3CA, Somatic mutation, hypoplasia

\section{Background}

The term "PIK3CA - related overgrowth spectrum" (PROS) has gained popularity in recent literature to describe a group of overgrowth syndromes/disorders caused by somatic PIK3CA mutations [1]. In 2014, Al-Qattan described a new overgrowth syndrome in three unrelated Saudi patients and named it "upper limb muscle overgrowth in a proximo-distal gradient with hypoplasia of the index finger" (upper limb MO-hypoplasia IF). As the name implies, the two characteristic clinical features of the syndrome are:muscle overgrowth of one or both upper limbs

\footnotetext{
* Correspondence: Balwim@ngha.med.sa

${ }^{\dagger}$ Mohammad M. Al-Qattan and Ali Hadadi contributed equally to this work. ${ }^{3}$ King Saud bin Abdulaziz University for Health Sciences, College of Medicine, Riyadh, Saudi Arabia

${ }^{4}$ Department of Pathology \& Laboratory Medicine, MC1122, King Abdulaziz Medical City, Ministry of National Guard Health Affairs, P.O Box 22490, Riyadh 11426, Kingdom of Saudi Arabia

Full list of author information is available at the end of the article
}

which is manifested in a proximal-to-distal gradient, and congenital hypoplasia of the index finger. Other features of the syndrome are: flexion contractures of the fingers, hyper-extension deformity of the metacarpophalangeal joint of the thumb, ulnar deviation of the index finger, and a wide palm with abnormal palmar creases. In all previously reported cases, MRI confirmed that the limb overgrowth is due to enlarged/aberrant muscles with no fatty infiltration or vascular malformations. The most characteristic plain X-ray feature was widening of the space between the second and third metacarpals. No genetic analysis was done in Al-Qattan report [2].

In this paper, we describe a new case of upper limb MO-hypoplasia IF syndrome and document that it is caused by the somatic PIK3CA mutation c.3140A $>\mathrm{G}$, p. His1047Arg. We also recruited one of the patients reported by $\mathrm{Al}$-Qattan [2]; and confirmed the presence of the same mutation. A review of the literature was also

(c) The Author(s). 2018 Open Access This article is distributed under the terms of the Creative Commons Attribution 4.0 International License (http://creativecommons.org/licenses/by/4.0/), which permits unrestricted use, distribution, and reproduction in any medium, provided you give appropriate credit to the original author(s) and the source, provide a link to the Creative Commons license, and indicate if changes were made. The Creative Commons Public Domain Dedication waiver (http://creativecommons.org/publicdomain/zero/1.0/) applies to the data made available in this article, unless otherwise stated. 
done for similar cases. Finally, we offer a wider classification of "PIK3CA - related pathology spectrum".

\section{Case presentation}

\section{Clinical description - patient \#1}

A two -month old male infant presented to the surgical clinic with overgrowth of the right upper limb. He was born vaginally at term following a normal pregnancy. The birth weight and length were at the 50th centile. Family history was unremarkable. On physical examination there was overgrowth of the right upper limb which manifested in a proximo-distal gradient (Fig. 1a). The index finger was hypoplastic and ulnarly deviated (Fig. 1b). The palm was wide with abnormal palmar creases (Fig. 1b). There was also hyper-extension deformity of the metacarpophalangeal joint of the thumb (Fig. 1b). No other abnormalities were noted on clinical examination. Plain X-ray of the arm/ forearm showed no abnormalities. X-ray of the hand confirmed the hypoplasia of the index finger and widening of the space between the second and the third metacarpals (Fig. 1c). MRI confirmed that the overgrowth was due to enlarged muscles with no fatty infiltration or vascular malformations (Fig. 1d). A muscle biopsy was taken from the volar forearm muscles. During surgery, the subcutaneous fat was noted to be normal and the muscles appeared hypertrophied with no other abnormalities (Fig. 1e).

\section{Clinical description - patient \#2}

We recruited case \#2 reported by Al-Qattan in 2014 [2]. The 11-year old boy had muscle overgrowth of both upper limbs, but the involvement of the right upper limb was much more pronounced than the left (Fig. 2). The patient had all the classic clinical andradiological features of the upper limb MO - hypoplasia IF syndrome and showed no other abnormalities. A muscle biopsy was taken from the right forearm muscles and surgical findings were similar to our first case.

\section{Ethical approval and consents}

Patients were assessed during their visit to the Plastic Surgery clinic. Detailed clinical data and radiological findings were obtained according to the Saudi Ministry of Health $(\mathrm{MOH})$ guidelines. Protocols for peripheral blood sample collection, muscles biopsies, and genomic analysis were approved by the Research Committee at the National Hospital of Riyadh, Saudi Arabia in compliance withthe Declaration of HelsinkiPrinciples. Peripheral blood and muscle biopsy samples were obtained
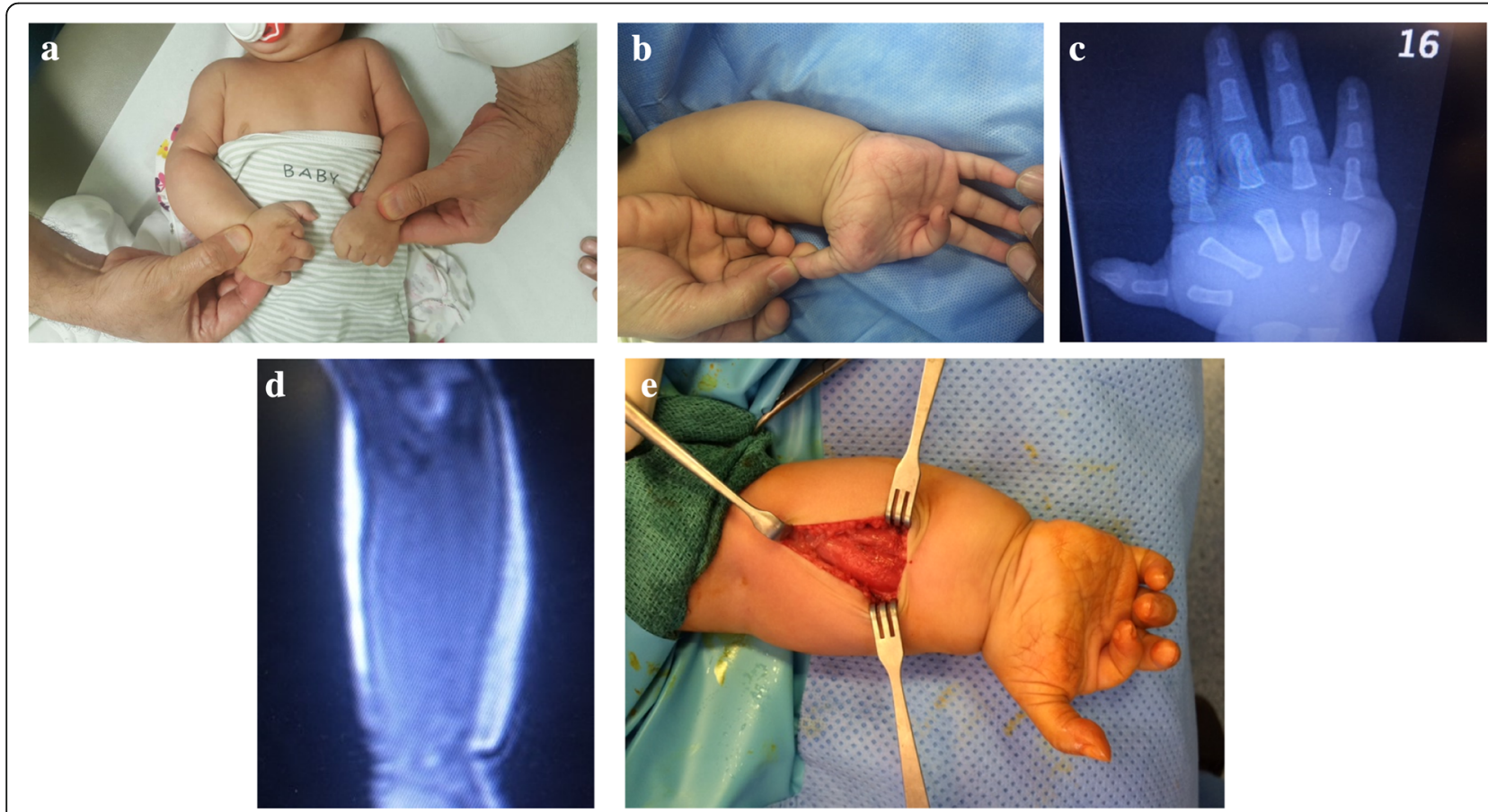

Fig. 1 A 2-month-old boy with upper limb MO-hypoplasia IF syndrome. a A view to compare the affected right upper limb to the unaffected left upper limb. Note that the overgrowth is more prominent in the hand/forearm than the arm. $\mathbf{b}$ A view of the hand showing hypoplasia and ulnar-deviation of the index finger. Note the wide palm with abnormal palmar creases as well as the hyperextension of the thumb. c Plain X-ray of the hand showing a short hypoplastic index finger and widening of the space between the second and the third metacarpal. $\mathbf{d}$ MRI of the forearm showing the "pure" muscle overgrowth. e A view during the muscle biopsy procedure. Note the bulky muscles with a normal subcutaneous fat layer 


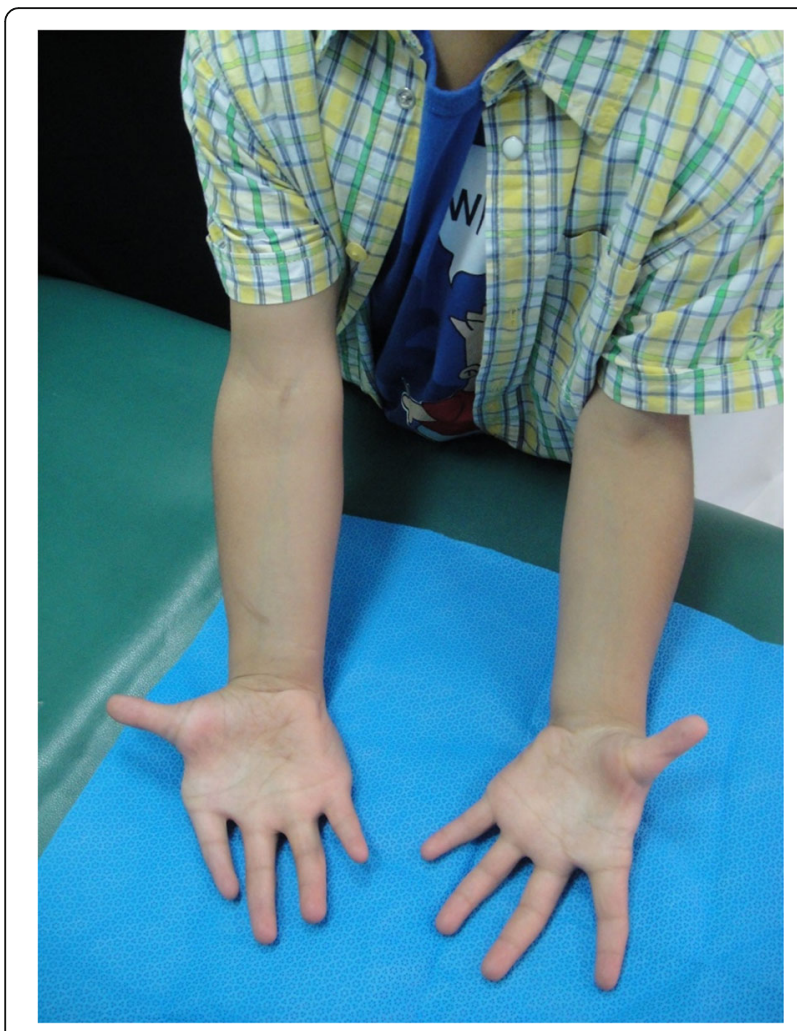

Fig. 2 Patient \#2 from Al-Qattan's report [2] who underwent genetic analysis. The muscle overgrowth is bilateral but it is more pronounced on the right

after signing a written informed consent form from all patients.

\section{PIK3CA mutational analysis}

Genomic DNA was extracted from the collected peripheral blood samples and muscle biopsies using Qiagen DNeasykit (Qiagen, Germany) according to the manufacturer's instructions. The region, exons and the intron/exons junctions of the PIK3CA gene were amplified by PCR and bidirectional sequences were performed using previously described primers byBachman et al. [3] using an ABI prism Big Dye Terminator v. 3.1 cycle sequencing kit (Applied Biosystems, Foster City, USA) and an ABI 3130 Genetic Analyzer sequencer (Applied Biosystems, Foster City, USA). Mutationswere identified by comparison to reference sequences (GenBank Accession No NM_006218.3; http:// www.ncbi.nlm.nih.gov) using CLC Genomics Workbench v 8.0 (CLC bio, Aarhus, Denmark) and these were checked against theupdatedSingle Nucleotide PolymorphismsDatabase (dSNPs; http://www.ncbi.nih.gov) and the Catalogue Of Somatic Mutation In Cancer (COSMIC, https://cancer. sanger.ac.uk). Furthermore, analysis of the mutation was evaluated using different bioinformatics tools including 'Mutation Taster' (http://www.mutationtaster.org) to predict confirmation of "disease causing" mutation.

\section{Discussion and conclusions}

Clinically, both of our patients had all the characteristic features of theupper limb MO-hypoplasia IF syndrome.Histologically, muscle biopsies from both patientsshowed hypertrophic muscle fibers with no fatty infiltration or vascular malformations.Molecular genetic analysis of both patients showed a similar somatic mutation within PIK3CA gene at exon20 (c.3140A >G, p. His1047Arg) in the genomic DNA obtained from the muscle biopsies (Fig. 3), but not from blood leucocytes.

The upper limb MO-hypoplasia IF syndrome is not as rare as previously thought. Upon reviewing the English literature prior to Al-Qattan [2] report, several similar cases were found in the Hand Surgery literature [4-9]. These hand surgeons commented on the muscle hypertrophy of the upper limbs as well as the aberrant muscles and the deviation of the fingers. However, when we examined the illustrations of these reports, we also found that hypoplasia of the index finger was a constant feature. We also found two similar cases reported in the

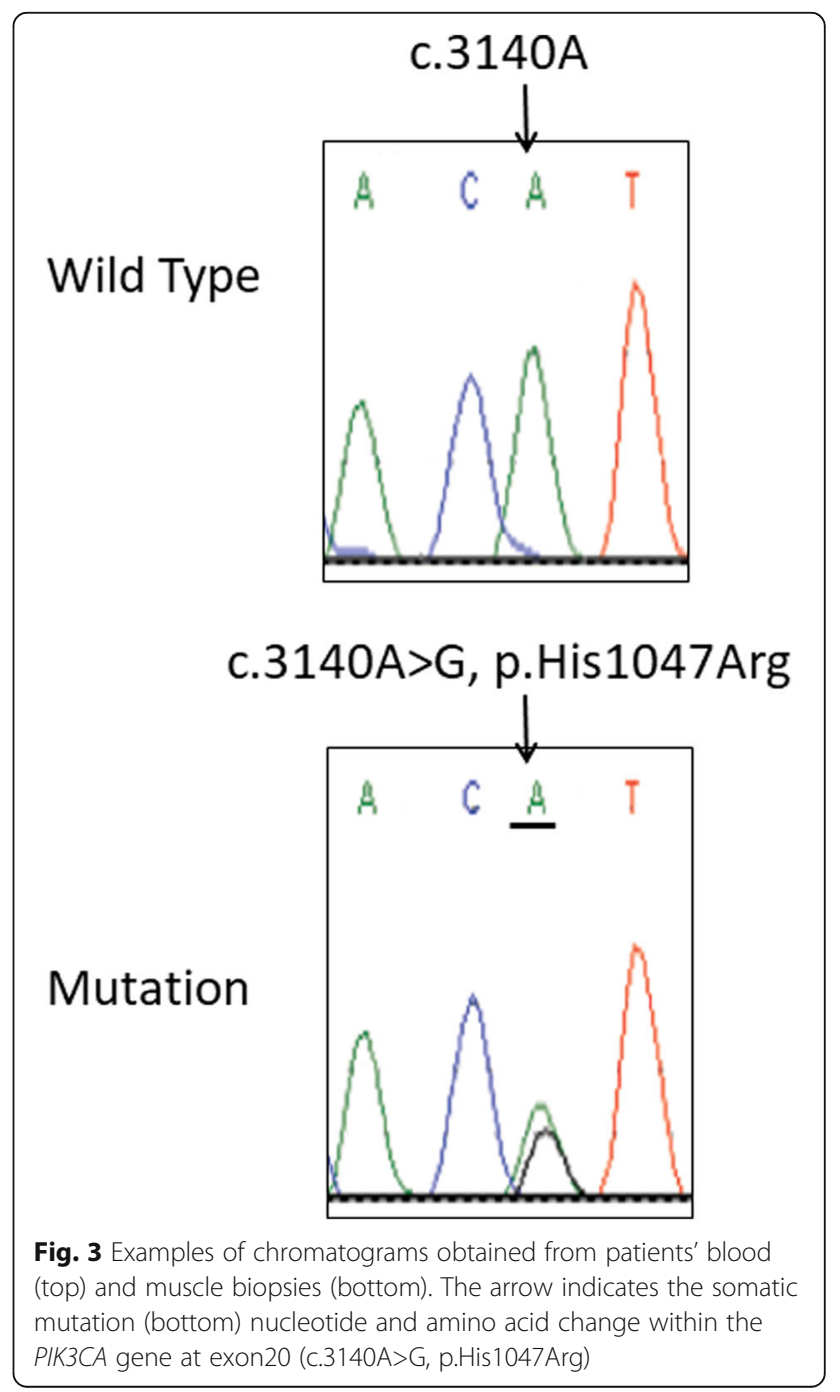


Genetics literature. Castiglioni et al. [10] reported on a 6-year old girl with unilateral isolated upper limb muscle overgrowth. The authors only commented on the ulnar drift of the index finger; although the illustrations also showed hypoplasia of the index finger. An open biopsy of the interosseous muscle was done and revealed the same somatic mutation in PIK3CA (p.3140A>G, p. His1047Arg). Rasmussen et al. [11] reported on a 20-year old female with bilateral upper limb muscle hypertrophy and concurrent upper back lipoma. The authors only commented on the overlapping of the index fingers over the middle fingers; although the illustrations also showed hypoplasia of both index fingers. A muscle biopsy also revealed the same somatic mutation in PIK3CA. Our review clearly confirms that the "upper limb MO-hypoplasia IF" syndrome is a unique entity that should be added to the PROS. The fact that all cases that underwent genetic analysis showed the exact same somatic mutation in PIK3CA is interesting. However, this does not mean that a genotype-phenotype correlation exists; since $70 \%$ of patients with PROS have one of three somatic mutations in PIK3CA: p. Glu542Lys, p. Glu545Lys, and p. His1047Arg [12]. These three hotspot mutations also make about $70 \%$ of PIK3CA somatic mutations associated with cancer [13].

We believe that a wider classification of "PIK3CA-related pathology spectrum" (PRPS) should be offered (Table 1) and should include somatic and germline mutations. This pathology spectrum should include cancer, benign skin lesions/ tumors, Cowden syndrome, isolated vascular malformations as well as the PROS [1, 12-25].The PROS should also be extended to include the "upper limb MO-hypoplasia IF" as well as the Klipple-Trenaunay syndrome as described by Yeung et al. [12]. We also recommend dividing the PROS into three sub-groups: PROS with brain involvement, PROS with multiple lipomatosis, and PROS without brain involvement / multiple lipomatosis. Our PRPS is summarized (Table 1). Note that our classification is based on pathological entities (which is more clinically oriented) and not based on genotype-phenotype correlations proposed in Mirzaaet al. [26].

Table 1 PIK3CA-Related Pathology Spectrum (PRPS)

\begin{tabular}{|c|c|c|}
\hline Pathology & Comments & Reference \\
\hline Cancers & $\begin{array}{l}\text { Several cancers are known to be associated with PIK3CA somatic mutations } \\
\text { such as cancer of the breast, colon, stomach, liver, lung and ovaries }\end{array}$ & [13] \\
\hline Benign skin lesions/ Tumors & $\begin{array}{l}\text { Seborrheic keratosis, epidermal nevi, Lichenoid keratosis, hydradenomapapilliferum } \\
\text { are associated with PIK3CAsomaticmutations }\end{array}$ & {$[1,12,14,15]$} \\
\hline Cowden syndrome type5 & $\begin{array}{l}\text { Cowden syndrome (multiple hamartomas of the mucous membrane and skin } \\
\text { lesions) is put in a separate group because it is associated with PIK3CA germline } \\
\text { and not somatic mutations }\end{array}$ & {$[16]$} \\
\hline Isolated vascular malformations & $\begin{array}{l}\text { Isolated lymphatic, venous and lymphatico-venous malformation are associated } \\
\text { with PIK3CA somatic mutations. }\end{array}$ & {$[12,17]$} \\
\hline $\begin{array}{l}\text { PROS (PIK3CA - Related overgrowth } \\
\text { spectrum) with brain involvement }\end{array}$ & $\begin{array}{l}\text { MCAP (Megalencephaly, capillarymalformation, polymicrogyria, syndactyly, } \\
\text { polydactyly), MPPH (Megalencephaly polymicrogyria, polydactyly, hydrocephalus), } \\
\text { DMEG (Dysplastic megalencephaly), Hemi-megalencephaly, and Focal cortical dys } \\
\text { plasiaare associated with PIK3CA somatic mutations }\end{array}$ & {$[1,18,19]$} \\
\hline $\begin{array}{l}\text { PROS with multiple lipomatosis as } \\
\text { the main presenting feature }\end{array}$ & $\begin{array}{l}\text { HHML (Hemihyperplasia-multiple lipomatosis), facial infiltrating lipomatosis (facial } \\
\text { lipomatosis, skeletal overgrowth, macrodontia, hemi-macroglossia, oral mucosal } \\
\text { neuromas), mesenteric lipomatosis (Mesenteric lipomatosis, and insulin } \\
\text { hypersensitivity are the main presenting features. Although the skin may have } \\
\text { subcutaneous lipomas, there is relative lack of subcutaneous adipose tissue), } \\
\text { multiple subcutaneous lipomatosis-scoliosis-multiple internal organ lymphatic } \\
\text { malformations described by Yeung et al. [12]. All of these disorders are associated } \\
\text { with PIK3CA somatic mutations }\end{array}$ & {$[1,12,18,20,21]$} \\
\hline Other PROS disorders & $\begin{array}{l}\text { CLOVES syndrome (Congenital, lipomatous overgrowth, vascular malformations, } \\
\text { epidermal nevi and skeletal/spinal anomalies.Splayed feet with macrodactyly and } \\
\text { wide sandal gap are characteristic), fibro-adipose overgrowth (FAO, progressive } \\
\text { segmental overgrowth of subcutaneous, muscular and visceral fibro-adipose tissue. } \\
\text { Skeletal overgrowth of the lower limb with macrodactyly of the feet are } \\
\text { characteristic), isolated macrodactyly of the hands/feet, nerve-oriented macrodactyly } \\
\text { (known in the hand surgery literature as lipo-fibromatous hamartoma of nerve with } \\
\text { macrodactyly because the macrodactyly is seen in the digital rays supplied by the } \\
\text { affected nerve). Rios et al. [24] reported on a case with nerve -oriented- } \\
\text { macrodactyly and concurrent muscle hypertrophy. Klippel-Trenaunay syndrome } \\
\text { (progressive growth of the lower limb with cutaneous capillary malformations and } \\
\text { deep vascular malformations), and upper limb MO - hypoplasia IF are also included } \\
\text { in this group. All of these disorders are associated with PIK3CA somatic mutations }\end{array}$ & $\begin{array}{l}{[1,12,18,22-25] \text { and }} \\
\text { the current report }\end{array}$ \\
\hline
\end{tabular}


The PIK3CA gene encodes the p110 $\alpha$ catalytic sub-unit of PI3K (phosphatidylinositol 3-kinase). All somatic and germline mutations of the PRPS are activating (gain-of-function) mutations of the PI3K pathway leading to enhanced cellular proliferation. The PI3K pathway (Fig. 4) is initiated by growth factor/cytokine stimulation of a receptor tyrosine kinase in the plasma membrane [27]. This activates PI3K (which is heterodimer composed of a regulatory sub- unit known as $\mathrm{p} 85 \alpha$ and a catalytic sub-unit known as p110 $\alpha$ ). The activated PI3K will then add a phosphate group to PIP2 to become PIP3 (phosphatidyl inositol bis-phosphate to phosphatidyl inositol tris-phosphate) at the plasma membrane lipids. The PIP3 will then recruit Akt1 (protein kinase B) to the plasma membrane, allowing PDK1 (phosphoinositide- dependent kinase 1) to phosphorylate and activate Akt1 at its activation loop site (Thr 308). Further activation of Akt1 requires its phosphorylation at another site (Ser 473) by mTORC2 (mechanistic Target of Rapamycin Complex-2). The fully activated Akt1 will then induce several cellular processes including stimulation of cell proliferation and suppression of apoptosis. The PI3K pathway is negatively regulated by PTEN (Phosphate and tensin homolog) and this is done by converting PIP3 into PIP2. Hence gain-of-function of PIK3CA, AKT1, and MTOR; or loss-of-function of PTEN will result in cancer, benign tumors, and overgrowth syndromes. For example, proteus syndrome (sporadic, mosaic, asymmetric and progressive overgrowth of body parts with cerebriform connective tissue nevi being characteristic of the syndrome) may be caused by gain-of-function somatic mutations of $A K T-1$ [28], or loss-of-function germline mutations of PTEN [29].Similarly, Cowden and Cowden-like syndromes are caused by loss-of-function germline PTEN mutations as well as gain-of-function germline mutations of PIK3CA and $A K T 1$ [16]. Finally, megalencephalysyndromes maybe caused by gain-of-function somatic mutations of PIK3CA (Table 1) or gain-of-function germline mutations of MTOR [30].

In conclusion, we describe a unique form of overgrowth syndrome caused by the PIK3CA somatic mutation: p. His1047Arg. We also review similar cases in the literature and offer a wider classification of PIK3CA - related pathology spectrum.

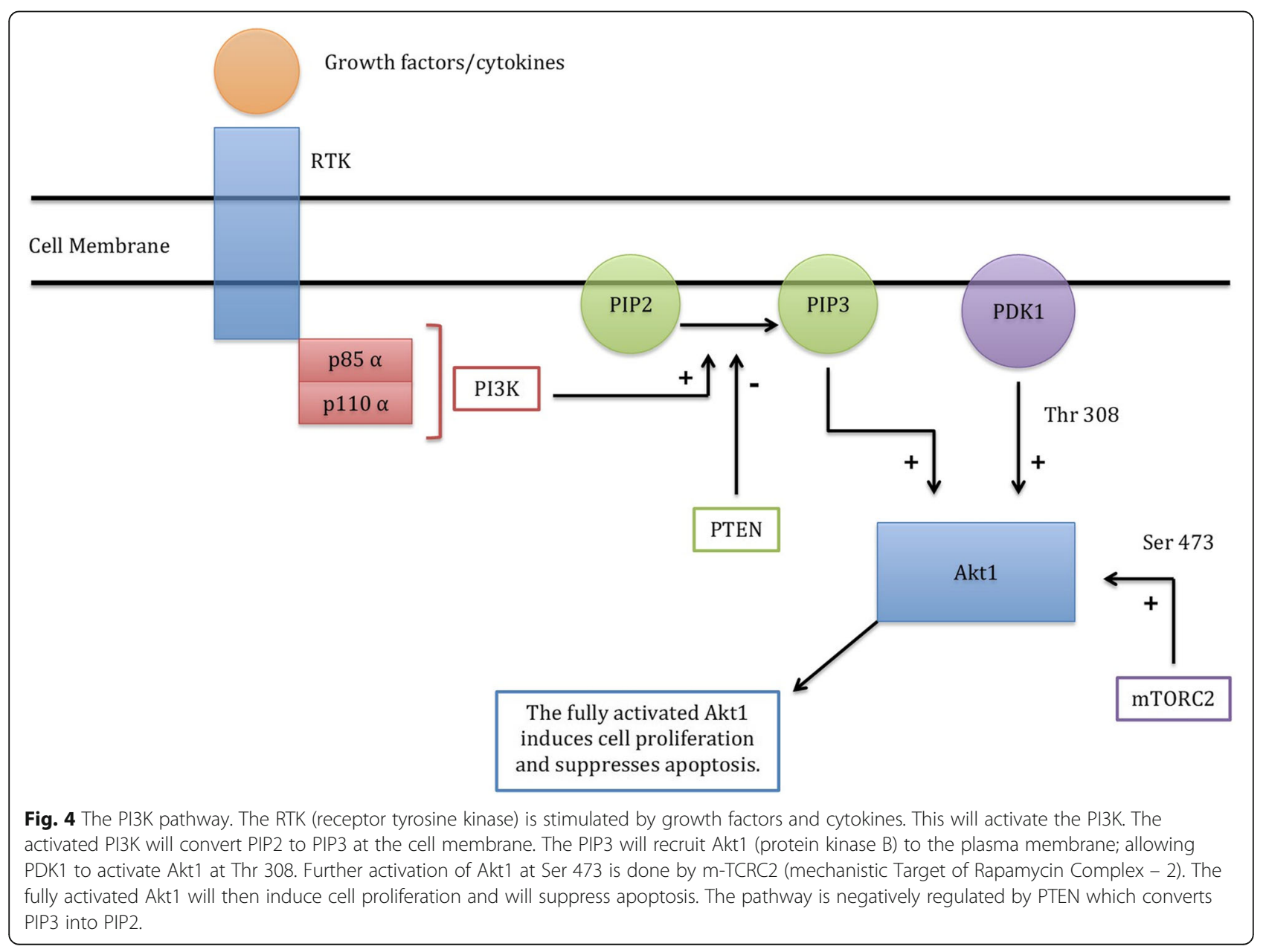




\section{Abbreviations}

MOH: Saudi Ministry of Health; PROS: PIK3CArelated overgrowth spectrum: PRPS: PIK3CA-Related Pathology Spectrum

\section{Acknowledgements}

The authors would like to thank Ms. Zoe P. Camarig for her assistance in editing and proofreading of the manuscript.

\section{Funding}

This work was supported by the College of Medicine Research Center, Deanship of Scientific Research, King Saud University, Riyadh, Saudi Arabia.

\section{Availability of data and materials}

The datasets used andanalyzedin the current study are available from the corresponding author upon request.

\section{Authors' contributions}

MMA and $\mathrm{AH}$ have contributed equally and were involved in the study design, organizing the study plan and preparing the manuscript. MMA, AMA and AAE examined the patients, collected the data, and participated in manuscript preparation.MAA was involved in the analysis, laboratory work, manuscript preparation, organizing and supervising the overall work. All authors have read and approved the final manuscript.

\section{Ethics approval and consent to participate}

Collection of sampleswas done following approval by the Institutional Review Board of the National Hospital of Riyadh, Saudi Arabia in compliance the Declaration of Helsinki principles. Parents of our patients signed written informed consents to participate in this study.

\section{Consent for publication}

A written consent for publication of clinical data and images was obtained from the parents of our patients. A copy of the written consent is available for review by the Editor of this journal.

\section{Competing interests}

The authors declare that they have no competing interests.

\section{Publisher's Note}

Springer Nature remains neutral with regard to jurisdictional claims in published maps and institutional affiliations.

\section{Author details}

'Division of Plastic Surgery, King Saud University, Riyadh, Saudi Arabia. ${ }^{2}$ Division of Plastic Surgery, King Abdulaziz Medical City, Ministry of National Guard Health Affairs, Riyadh, Saudi Arabia. ${ }^{3}$ King Saud bin Abdulaziz University for Health Sciences, College of Medicine, Riyadh, Saudi Arabia. ${ }^{4}$ Department of Pathology \& Laboratory Medicine, MC1122, King Abdulaziz Medical City, Ministry of National Guard Health Affairs, P.O Box 22490, Riyadh 11426 , Kingdom of Saudi Arabia. ${ }^{5}$ Department of Medical Genomics Research, King Abdullah International Medical Research Center, Ministry of National Guard Health Affairs, Riyadh, Saudi Arabia.

\section{Received: 26 May 2018 Accepted: 27 August 2018}

\section{Published online: 04 September 2018}

\section{References}

1. Keppler-Noreuil KM, Rios JJ, Parker VE, Semple RK, Lindhurst MJ, Sapp JC, Alomari A, Ezaki M, Dobyns W, Biesecker LG. PIK3CA-related overgrowth spectrum (PROS): diagnostic and testing eligibility criteria, differentia diagnosis, and evaluation. Am J Med Genet A. 2015;167A(2):287-95.

2. Al-Qattan MM. Muscle overgrowth of the upper limb in a proximo-distal gradient and concurrent hypoplasia of the index finger. J Pediatr Orthop. 2014;34(7):715-9.

3. Bachman KE, Argani P, Samuels Y, Silliman N, Ptak J, Szabo S, Konishi H, Karakas B, Blair BG, Lin C, et al. The PIK3CA gene is mutated with high frequency in human breast cancers. Cancer Biol Ther. 2004;3(8):772-5.

4. So YC. An unusual association of the windblown hand with upper limb hypertrophy. J Hand Surg Br. 1992;17(1):113-7.

5. Seto Y, Nishijima N, Mototsu M. Congenital anomaly of the hand due to aberrant muscles. Central Japan J Orthop Surg Traumatol. 1992;34:985-7.
6. Lanz U, Hahn P, Varela C. Congenital unilateral muscle hyperplasia of the hand with ulnar deviation of the fingers. J Hand Surg Br. 1994;19:683-8.

7. Tanabe K, Tada K, Doi T. Unilateral hypertrophy of the upper extremity due to aberrant muscles. J Hand Surg Br. 1997:22(2):253-7.

8. Teoh LC, Yong FC, Guo CM. Congenital isolated upper limb hypertrophy with hand abnormality--a report of 2 cases. J Hand Surg Br. 2001;26(5): 492-5.

9. Takka S, Doi K, Hattori Y, Kitajima I, Sano K. Proposal of new category for congenital unilateral upper limb muscular hypertrophy. Ann Plast Surg. 2005;54(1):97-102

10. Castiglioni C, Bertini E, Orellana P, Villarroel C, Las Heras F, Hinzpeter D, Paolinelli P, Bevilacqua JA, Alvarez K. Activating PIK3CA somatic mutation in congenital unilateral isolated muscle overgrowth of the upper extremity. Am J Med Genet A. 2014;164A(9):2365-9.

11. Rasmussen M, Sunde L, Weigert KP, Bogaard PW, Lildballe DL. Segmental overgrowth syndrome due to an activating PIK3CA mutation identified in affected muscle tissue by exome sequencing. Am J Med Genet A. 2014; 164A(5):1318-21.

12. Yeung KS, Ip JJ, Chow CP, Kuong EY, Tam PK, Chan GC, Chung BH. Somatic PIK3CA mutations in seven patients with PIK3CA-related overgrowth spectrum. Am J Med Genet A. 2017:173(4):978-84.

13. Filipenko ML, Os'kina NA, Oskorbin IA, Mishukova OV, Ovchinnikova LK, Gershtein ES, Kushlinskii NE. Association between the prevalence of somatic mutations in PIK3CA gene in tumors and clinical and morphological characteristics of breast cancer patients. Bull Exp Biol Med. 2017;163(2):250-4.

14. Goto K, Maeda D, Kudo-Asabe Y, Hibiya T, Hayashi A, Fukayama M, Ohashi K, Goto A. PIK3CA and AKT1 mutations in hidradenoma papilliferum. J Clin Pathol. 2017;70(5):424-7.

15. Hafner C, López-Knowles E, Luis NM, Toll A, Baselga E, Fernández-Casado A, Hernandez S, Ribé A, Mentzel T, Stoehr R, et al. Oncogenic PIK3CA mutations occur in epidermal nevi and seborrheic keratoses with a characteristic mutation pattern. Proc Natl Acad Sci U S A. 2007:104(33): 13450-4.

16. Orloff MS, He X, Peterson C, Chen F, Chen JL, Mester JL, Eng C. Germline PIK3CA and AKT1 mutations in Cowden and Cowden-like syndromes. Am J Hum Genet. 2013:92(1):76-80.

17. Limaye N, Kangas J, Mendola A, Godfraind C, Schlögel MJ, Helaers R, Eklund L, Boon LM, Vikkula M. Somatic activating PIK3CA mutations cause venous malformation. Am J Hum Genet. 2015;97(6):914-21.

18. Keppler-Noreuil KM, Sapp JC, Lindhurst MJ, Parker VE, Blumhorst C, Darling T, Tosi LL, Huson SM, Whitehouse RW, Jakkula E, et al. Clinical delineation and natural history of the PIK3CA-related overgrowth spectrum. Am J Med Genet A. 2014;164A(7):1713-33,

19. Jansen LA, Mirzaa GM, Ishak GE, O'Roak BJ, Hiatt JB, Roden WH, Gunter SA, Christian SL, Collins S, Adams C, et al. PI3K/AKT pathway mutations cause a spectrum of brain malformations from megalencephaly to focal cortical dysplasia. Brain. 2015;138:1613-28.

20. Couto JA, Konczyk DJ, Vivero MP, Kozakewich HPW, Upton J, Fu X, Padwa B MJB, Warman ML, Greene AK. Somatic PIK3CA mutations are present in multiple tissues of facial infiltrating lipomatosis. Pediatr Res. 2017;82(5): 850-4.

21. Cohen AS, Townsend KN, Xiang QS, Attariwala R, Borchers C, Senger C, Picker W, Levi J, Yewchuk L, Tan J, et al. Somatic mosaicism for the $\mathrm{p}$. His1047Arg mutation in PIK3CA in a girl with mesenteric lipomatosis. Am J Med Genet A. 2014:164A(9):2360-4.

22. Martinez-Lopez A, Blasco-Morente G, Perez-Lopez I, Herrera-Garcia JD, Luque-Valenzuela M, Sanchez-Cano D, Lopez-Gutierrez JC, Ruiz-Villaverde R. Tercedor-Sanchez J. CLOVES syndrome: review of a PIK3CA-related overgrowth spectrum (PROS). Clin Genet. 2017;91(1):14-21.

23. Lindhurst MJ, Parker VE, Payne F, Sapp JC, Rudge S, Harris J, Witkowski AM, Zhang Q, Groeneveld MP, Scott CE, et al. Mosaic overgrowth with fibroadipose hyperplasia is caused by somatic activating mutations in PIK3CA. Nat Genet. 2012;44(8):928-33.

24. Rios JJ, Paria N, Burns DK, Israel BA, Cornelia R, Wise CA, Ezaki M. Somatic gain-of-function mutations in PIK3CA in patients with macrodactyly. Hum Mol Genet. 2013:22(3):444-51.

25. Al-Qattan MM. Lipofibromatous hamartoma of the median nerve and its associated conditions.J Hand Surg Br. 2001:26(4):368-72.

26. Mirzaa G, Timms AE, Conti V, Boyle EA, Girisha KM, Martin B, Kircher M, Olds C. Juusola J, Collins S, et al. PIK3CA-associated developmental disorders exhibit distinct classes of mutations with variable expression and tissue 
distribution. JCI Insight. 2016;1(9):e87623. https://doi.org/10.1172/jci.insight. 87623

27. Hemmings BA, Restuccia DF. PI3K-PKB/Akt pathway. Cold Spring Harb Perspect Biol. 2012;4(9):a011189. https://doi.org/10.1101/cshperspect.a011189.

28. Lindhurst MJ, Sapp JC, Teer JK, Johnston JJ, Finn EM, Peters K, Turner J, Cannons $J \mathrm{~L}$, Bick D, Blakemore $\mathrm{L}$, et al. A mosaic activating mutation in AKT1 associated with the Proteus syndrome. N Engl J Med. 2011;365(7):611-9.

29. Smith JM, Kirk EP, Theodosopoulos G, Marshall GM, Walker J, Rogers M, Field M, Brereton JJ, Marsh DJ. Germline mutation of the tumor suppressor PTEN in Proteus syndrome. J Med Genet. 2002;39(12):937-40.

30. Smith LD, Saunders CJ, Dinwiddie DL, Atherton AM, Miller NA, Soden SE, Farrow EG, Abdelmoity ATG, Kingsmore SF. Exome sequencing reveals De novo germline mutation of the mammalian target of rapamycin (mTOR) in a patient with megalencephaly and intractable seizures. J Genomes Exomes. 2013;2:63-72.

Ready to submit your research? Choose BMC and benefit from:

- fast, convenient online submission

- thorough peer review by experienced researchers in your field

- rapid publication on acceptance

- support for research data, including large and complex data types

- gold Open Access which fosters wider collaboration and increased citations

- maximum visibility for your research: over $100 \mathrm{M}$ website views per year

At $\mathrm{BMC}$, research is always in progress.

Learn more biomedcentral.com/submissions 